\title{
Molecular Characterization and Expression Analysis of aflR, aflS, and aflD in Non-Aflatoxigenic and Aflatoxigenic Aspergillus flavus Treated with Gallic Acid.
}

\author{
Ghada M. El-Sayed ${ }^{1}$, Rasha G. Salim ${ }^{1}$, Soher E-S. Aly ${ }^{2}$ and Nivien A. Abosereh, ${ }^{3, *}$ \\ ${ }^{1}$ Microbial Genetic Department, National Research Centre, Dokki, Cairo, Egypt; ${ }^{2}$ Food Toxicology and Contaminants Department, \\ National Research Centre, Dokki, Cairo, Egypt; ${ }^{3}$ Microbial Genetic Department, National Research Centre, Dokki, Cairo, Egypt.
}

Received: June 6, 2020; Revised: October 10, 2020; Accepted: Nov 3, 2020

\begin{abstract}
In this study, from five Aspergillus flavus strains, only three strains have been aflatoxin B producers. Gallic acid as antioxidant was used to assay its potential in aflatoxin diminishing. Gallic acid treated aflatoxin B producing isolates showed a slightly inhibition in aflatoxin production and a remarked diminishing in spore formation and growth as compared with untreated isolates. Three genes, $a f l R$, $a f l S$, and $a f L D$ were successfully amplified by a conventional polymerase chain reaction in aflatoxigenic and gallic acid treated Aspergillus flavus strains. These genes have been sequenced and deposited in Genbank under the accession numbers LC537158, MW055253, and LC537157, respectively. It has been demonstrated that there was no difference in nucleotide sequences in the amplified fragments of these genes in both aflatoxigenic and gallic acid treated Aspergillus flavus isolates, qRT-PCR was employed to test the effect of gallic acid on the transcription of aflR, aflS, and aflD genes and that ensured the negative effect of gallic acid on these genes transcription and therefore production of aflatoxin production
\end{abstract}

Keywords :Aspergillus flavus, conventional PCR, Gallic acid, qRT- PCR

\section{Introduction}

Production of acute toxic, mutagenic, teratogenic, or estrogenic responses in higher vertebrates was reported via mycotoxin exosure such as Aflatoxins (AF) (Jelineket al., 1989); they are secondary metabolites, poly-ketide that have been produced by Aspergillus flavus and Aspergillus parasiticus. Aflatoxins are carcinogenic and contaminate food and feed worldwide (Bhatnagaret al., 1987). The complete elucidation of the gene cluster involved in aflatoxin biosynthesis in A parasiticus was achieved by Yu and Ehrlich (2002) and Yu et al. (2004); another study conducted by O'Brian et al. (2007) demonstrated the role of microarray to explain the regulation of aflatoxin biosynthesis genes.

Aflatoxin Genes in A. flavus and A. parasiticus have highly homologous sequences and the same order within the cluster. Aflatoxin B1 (AFB1) and B2 (AFB2) are known to be produced by $A$. flavus strains, whereas $A$. parasiticus produces aflatoxins B1, B2, G, and G2 (Giorniet al., 2007). Yan et al. (2012) reported the opportunistic and pathogenic infection of A. flavus for humans and animals besides its pathogenicity for plants. In the 1960s, aflatoxins, the basic reason for Turkey-X disease, were reported to be mainly produced by A. flavus (Nesbitt et al., 1962). While aflatoxins are considered the first fungal secondary metabolites shown to have all genes organized within a DNA cluster, there have since been significant efforts to realize regulatio $\mathrm{n}$ mechanism involved in aflatoxin biosynthesis.

Several interconnecting networks are involved in the regulation of $\mathrm{AF}$ biosynthesis which can be divided into three parts; the most important one comprises the regulation in the AF biosynthetic by aflR and aflS, positioned adjacent to each other in a $70 \mathrm{~kb}$ DNA cluster (Desjardins and Proctor, 2007).These genes are differentially transcribed with independent promoters; with short intergenic regions that share binding sites for regulatory elements or other transcription factors (Ehrlich et al., 2005). Woloshuk et al. (1994) and Yu et al. (1996) reported that a putative 47-kDa protein encoded by the gene of aflR, has a similar sequence to a zinc binucleate cluster DNA-binding protein, Todd and Andrianopoulos (1997) classified these proteins and renamed them as $\mathrm{Zn}$ (II) 2Cys6 proteins. aflR is a remarkable gene in $\mathrm{AF}$ biosynthesis for the following discoveries: Yu et al. (1996) take up aflR from A. flavus to drive ST cluster expression in an $A$. nidulans which lack $a f l R$ despite clear differences in AF biosynthesis pathway. Another study conducted by Lee et al. (2007) announced the presence of differences in PacC and AreA binding sites, promoter regulatory elements for aflR in A. parasiticus and A. flavus aflatoxin biosynthesis. Carbone et al. (2007) reported the presence of conserved domain of the aflR gene in both A. nidulans and A. fumigatus.

Another gene, aflS, has a precise role in AF biosynthesis. A study by Meyers et al. (1998) observed

\footnotetext{
* Corresponding author e-mail: nivienabdelrahman@yahoo.com.
} 
unchanged mRNA expression levels of genes, aflC, aflD, aflM, and aflP in an aflS disrupted strain, with all this; AF pathway intermediates could not be converted to aflatoxin. Regarding a relationship between AFLS (a protein encoded by aflS) and AFLR (a protein encoded by afIR), Chang (2004) showed that activation of AFLR requires AFLS binding in A. parasiticus. However, in A. flavus, there was no need of AFLS to activate AFLR in AF biosynthesis (Du et al., 2007), while they explained the roles of aflR and aflS as follows: transcription of early and mid-aflatoxin pathway genes require AFLR, but AFLS enhances this pathway.

Several environmental and cultural conditions such as light, temperature, $\mathrm{pH}$, nitrogen, carbon source, and metals can modulate AF biosynthesis (Calvo et al., 2004; Price, 2005). Over the past decade, research proved the increase in AF production by oxidative stress (Reverberi et al., 2008); antioxidants, for example, Gallic and caffeic acid reduce $\mathrm{AF}$ production via expression reduction or inhibition of some AF pathway genes such as aflD (nor-1) (Mahoney and Molyneux, 2004). Kim et al. (2008) announced the down-regulation of the most genes in AF biosynthesis due to caffeic acid treatment using microarray technique. Reverberi et al. (2008) also used glucans from Lentinulaedodes to induce the antioxidant enzymes which subsequently caused to delay in aflR transcription as well as AF cluster genes. Several studies conducted different genes assigned in aflatoxin biosynthesis, for example, The nor-1(aflD), apa-2, and omt-1 (omtA) genes by Shapira et al. (1996), The omt-1, nor-1, and ver-1 genes individually (Färber et al., 1997) and aflR, aflJ, and omtB genes (Rahimi et al., 2008).

The objective of this study was to investigate the $a f l R$, $a f I S$, and aflD genes profile in aflatoxigenic and nonaflatoxigenic isolates of the $A$. flavus using genomic DNA as a template by traditional PCR and assay the potential of gallic acid in aflatoxin suppression through down regulation of $a f l R$, aflS, and $a f I D$ using Rti-PCR technique

\section{Materials and Methods}

\subsection{Culture Conditions and Fungal Strains}

Five strains of $A$. flavus isolated from contaminated food, used in this study, were friendly provided from the toxicology department, National Research Centre, Egypt. About $10^{3}$ spores A. flavus were inoculated into $250 \mathrm{~mL}$ Erlenmeyer flasks containing $50 \mathrm{~mL}$ Potato dextrose broth (PDB), cultured for three days at $28^{\circ} \mathrm{C}, 200 \mathrm{rpm}$ incubator (thermoscientific, UK) and Potato dextrose agar (PDA Difco) at $28^{\circ} \mathrm{C}$ for three for further analysis.

\subsection{Aflatoxin Analysis Using High Performance Liquid Chromatography (HPLC)}

A total of $10^{3}$ A. flavus spores were inoculated on PDB medium and cultured at $28^{\circ} \mathrm{C}, 200 \mathrm{rpm}$ incubator (thermoscientific, UK) for three days. Aflatoxin was extracted from $50 \mathrm{~mL}$ culture medium for each sample by high performance liquid chromatography according to (Yu et al., 2004 and Salim et al., 2019).

\subsection{Investigation the effect of gallic acid on aflatoxin} production and colony diameter

A. flavus isolate 5 (the highest aflatoxin producer) was cultured on both PDB for aflatoxin analysis, and PDA media for measurement of colony diameter, supplemented with a concentration of $1 \%$ gallic acid (w/v), for three days at $28^{\circ} \mathrm{C}$, but only, $200 \mathrm{rpm}$ shaking conditions in case of PDB (treatment) in parallel with media without gallic acid (control).

\subsection{Isolation, Molecular Detection and Sequencing of aflR, aflS and aflD Genes}

\subsubsection{Extraction of Genomic DNA from Aspergillus flavus Isolates}

One strain of aflatoxigenic and another of nonaflatoxigenic A. flavus strains were separately grown on a100 mL conical flask ((Pyrex, USA) containing $20 \mathrm{ml}$ PDB without $1 \%(\mathrm{w} / \mathrm{v}) \mathrm{GA}$, (control) and with GA (treatment). Incubation was at $28 \mathrm{C}$ for 3-7 days. About $100 \mathrm{mg}$ mycelium was scraped off and used for genomic DNA extraction as follows: it was ground to a fine powder with liquid nitrogen, fine powder was subsequently put into a $1.5 \mathrm{~mL}$ sterile Eppendorf. Plant Genomic DNA Miniprep Kit (QIAamp DNA Mini Kit, QIAGEN, Germany) was used to extract DNA. DNA was used as a template for PCR amplification of aflR, aflS, and aflD for both aflatoxigenic and non-aflatoxigenic isolates.

\subsubsection{Primer Design and PCR Optimization}

Simultaneously, based on (http://frodo.wi.mit.edu/primer3/), all primers used for detection, and sequencing of aflatoxin genes were developed using NCBI reference sequences. These primers are listed in Table 1 . The primers were synthesized by HVD life sciences GMBH, Germany. Genomic DNA of A. flavus, as a template, was conducted with GeneAmp PCR system (PerkinElmer, Norwalk, Connecticut, USA). According to the method described by Ausubel et al. (1990), amplification was carried out in a $50 \mu 1$ reaction mixture using a PCR master mix kit (Qiagen, Germany). The following program was used: $94^{\circ} \mathrm{C}$ for 3 min as initial denaturation step, 35 cycles start with $94^{\circ} \mathrm{C}$ for 30 sec for denaturation, $55^{\circ} \mathrm{C}$ for $30 \mathrm{sec}$ for annealing and $72^{\circ} \mathrm{C}$ for $30 \mathrm{sec}$ for extension, finally, an extension step at $72^{\circ} \mathrm{C}$ for $10 \mathrm{~min}$. The PCR products were separated on $1 \%$ agarose gel using TAE buffer $1 \mathrm{X}(\mathrm{pH}=8.3)$ and run at $80 \mathrm{~V}$ for 45 $\mathrm{min}$, the bands were isolated and purified after agarose gel electrophoresis using a gel extraction kit (Qiagen, Germany). Purified gene fragments were sent to (Clinilab, colors lab, Egypt) for sequencing. The obtained sequences were compared to other known sequences found in Genbank database via the Blast program (http://www.ncbi.nlm.nih.gov/BLAST/).

Table1.The primers used in PCR amplification of aflR, aflS, and aflD

\begin{tabular}{lll}
\hline primers & Sequence $\left(5^{\prime} \rightarrow 3^{\prime}\right)$ & $\begin{array}{l}\text { NCBI } \\
\text { reference } \\
\text { sequence }\end{array}$ \\
\hline AFLR_F & GGATGAGGAAGACCAGCCGC & AY650938 \\
AFLR_R & CCTGTCATCTGCTCCTGGCG & \\
\hline AFLS_F & GGCCGAAGATTCCGCTTGGA & FN398168 \\
AFLS_R & GAGCGAGGGCAACAACCAGT & \\
\hline AFLD_F & CTGACGGCGTACGGAGTGTC & MH280091 \\
AFLD_R & GAGCACAGATGCCTGCCACA & \\
\hline
\end{tabular}

Notes: ((AFLR _F and AFLR _R, are forward and reverse primers for aflR PCR amplification, AFLS _F and AFLS _R, are forward and reverse primers for afIS PCR amplification, and 
AFLD_F and AFLD _R, are forward and reverse primers for aflD PCR amplification).

The obtained Sequences were translated to amino acids using https://web.expasy.org/translate/. Deduced protein sequences of all genes were aligned using CLUSTAL multiple sequence alignment using MUSCLE 3.8 analysis according to Thompson et al. (1994).

\subsubsection{Isolation of Total RNA}

Total RNA was isolated from GA untreated aflatoxigenic A. flavus (control) and GA treated one (treatment) by following the manufacturer's instructions of standard TRIzol ${ }^{\circledR}$ Reagent extraction method (cat\#15596026, Invitrogen, Germany). Purity assessment of total RNA was done by the $260 / 280 \mathrm{~nm}$ ratio between 1.8 and 2.1(https://www.agilent.com/cs/library/applications).

Additionally, visualization of $28 \mathrm{~S}$ and $18 \mathrm{~S}$ bands was used to assure RNA integrity via formaldehyde-containing agarose gel electrophoresis. For reverse transcription (RT), Aliquots of RNA were used immediately (Mahrous et al., 2020).

2.4.4. Reverse Transcription (RT) Reaction and cDNA Synthesis

According to the manufacturer's instructions of RevertAid $^{\mathrm{TM}}$ First Strand cDNA Synthesis Kit (MBI Fermentas, Germany), RNA isolated control and treated samples were reverse transcribed into cDNA in a total volume of $20 \mu \mathrm{l}$. The thermocycler (Biometra $\mathrm{GmbH}$, Göttingen, Germany) was used for carrying out the RT reaction at $25^{\circ} \mathrm{C}$ for $10 \mathrm{~min}$, followed by $1 \mathrm{~h}$ at $42^{\circ} \mathrm{C}$, and the reaction was stopped by heating for $5 \mathrm{~min}$ at $99{ }^{\circ} \mathrm{C}$. Then, the reaction tubes were flash-cooled in an ice chamber until getting used for DNA amplification via qRT-PCR .

\subsubsection{Quantitative Real Time-Polymerase Chain Reaction (qRT-PCR)}

StepOne $^{\mathrm{TM}}$ Real-Time PCR System from Applied Biosystems (Thermo Fisher Scientific, Waltham, MA USA) was used to determine the control and treated samples of fungal genes transcripts. Sequencing results of different genes were used to design gene specific primers, for qPCR by using the Primer3 program (http://frodo.wi.mit.edu/cgi-bin/primer3/

primer3_www.cgi)._PCR reactions were set up in $25 \mu \mathrm{L}$ reaction mixtures containing $12.5 \mu \mathrm{L} 1 \times$ SYBR ${ }^{\circledR}$ Premix Table 2. Aflatoxins production from Aspergillus flavus isolates

\begin{tabular}{|c|c|c|c|c|c|}
\hline Fungal isolates & sample name & $\begin{array}{l}\text { Production of } \\
\text { mycotoxins }\end{array}$ & Mycotoxins types & $\begin{array}{l}\text { Mycotoxin production } \\
\text { ug/ml }\end{array}$ & $\begin{array}{l}\text { Total Mycotoxins } \\
\text { production ug/ml }\end{array}$ \\
\hline \multirow[t]{8}{*}{ A. flavus } & isolate 1 & + & AFB1, AFB2 & $8.63 \pm 2.1$ & 11.17 \\
\hline & & + & & $2.54 \pm 0.56$ & \\
\hline & isolate 2 & + & AFB1, AFB2 & $18.22 \pm 3.2$ & 26.65 \\
\hline & & + & & $8.43 \pm 1.7$ & \\
\hline & isolate 3 & - & -- & $\mathrm{ND}$ & $\mathrm{ND}$ \\
\hline & isolate 4 & - & -- & $\mathrm{ND}$ & ND \\
\hline & isolate 5 & + & AFB1, AFB2 & $23.30 \pm 3.12$ & 34.97 \\
\hline & & + & & $11.67 \pm 2.54$ & \\
\hline
\end{tabular}

ExTaqTM (TaKaRa, Biotech. Co. Ltd.), $0.5 \mu \mathrm{L}$ of $0.2 \mu \mathrm{M}$ sense primer, $0.5 \mu \mathrm{L}$ of $0.2 \mu \mathrm{M}$ antisense primer, $6.5 \mu \mathrm{L}$ distilled water, and $5 \mu \mathrm{L}$ of cDNA template.

The reaction program was allocated to 3 steps. Firstly, it started at $95.0^{\circ} \mathrm{C}$ for $3 \mathrm{~min}$. Secondly, 40 cycles in which each cycle divided to 3 steps: (a) at $95.0^{\circ} \mathrm{C}$ for $15 \mathrm{sec}$; (b) at $55.0^{\circ} \mathrm{C}$ for $30 \mathrm{sec}$; and (c) at $72.0^{\circ} \mathrm{C}$ for $30 \mathrm{sec}$. thirdly, 71 cycles started at $60.0^{\circ} \mathrm{C}$ and every $10 \mathrm{sec}$, it increased about $0.5^{\circ} \mathrm{C}$ until reach to $95.0^{\circ} \mathrm{C}$. Each experiment included a distilled water control. GAPDH (housekeeping gene) was used as a control gene for differences in total cDNA input between samples. To check the quality of the used primers, a melting curve analysis was performed at $95.0^{\circ}$ at the end of each qRT-PCR. We were careful to make three replicates for each experiment. The relative amount of the genes of interest was calculated according to the method described by Ruijter et al. (2009).

\subsection{Statistical Analysis}

All the wet-lab experiments were conducted in triplicate. The data were subjected to analysis of variance and Duncan's multiple rang test was used to differentiate means at 5\% (Duncan, 1955). The error bars in all figures indicate the standard error of the mean.

\section{Results}

\subsection{Identification of Aflatoxin production Using High Performance Liquid Chromatography (HPLC) in A. flavus}

Direct extraction of aflatoxins from A. flavus cultures filtrates via chloroform and subsequent analysis by (HPLC), enables us to identify of AFB1, and AFB2 from three A. flavus isolates. The total AF of these strains are reported in (table 2) as follows; isolate $1(11.17 \mathrm{ug} / \mathrm{ml})$, isolate $2(26.65 \mathrm{ug} / \mathrm{ml})$, and isolate5 $(34.97 \mathrm{ug} / \mathrm{ml})$. The concentrations of aflatoxin $(\mathrm{ug} / \mathrm{ml})$ were calculated in three replicates of cultures average for every isolate and expressed as mean \pm SEM (Standard Error of the Mean). Simultaneously, these toxins were not detected in isolate 3 and isolate 4 . In this research, Isolate 5 , as aflatoxigenic and isolate 3 as non-aflatoxigenic samples were taken as examples to elucidate the molecular differences on the level of aflR, aflS, and aflD genes in both of them and investigate the effect of GA on aflatoxin biosynthesis in $A$. flavus strain no.5. 
3.2. Molecular Identification and Sequencing of aflR, aflS and aflD in Aflatoxigenic and non-Aflatoxigenic A. flavus isolates

Interestingly, unexpected results were observed, whereas AFLR _F and AFLR_R specific primers succeeded in aflR amplification at $\sim 320$ bp in both aflatoxigenic and non-aflatoxigenic $A$. flavus isolates figure (1a), the same situation occurred in aflS, 550 bp using AFLS _F and AFLS_R specific primers figure (1b), and $a f l D, \sim 420$ bp using AFLD _F and AFLD_R specific primers figure (1c) using genomic DNA as a template.

These amplified bands were isolated, purified from agarose gel, and subjected to nucleotide sequencing. The amplified regions of the isolated genes using the previously mentioned primers showed no differences in nucleotides sequences in the case of aflatoxigenic and nonaflatoxigenic isolates. Nucleotide sequences of genes were submitted to (https://www.ncbi.nlm.nih.gov/) and took accession numbers LC537158, MW055253, and LC537157 for aflR, aflS and aflD, respectively.

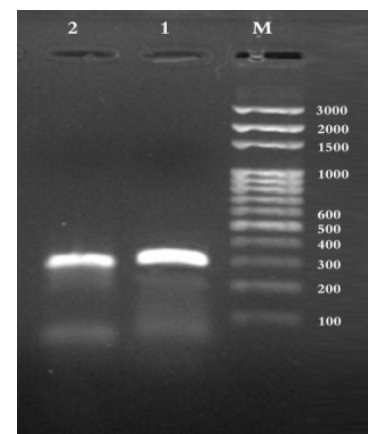

a



b



C

Figure 1. Agarose gel electrophoresis of PCR amplification (a): aflR, 320 bp in aflatoxigenic isolate 5 (lane1) and non-aflatoxigenic isolate 3 (lane 2). (b): aflS, 550 bp in aflatoxigenic isolate 5 (lane 1) and non-aflatoxigenic isolate 3 (lane 2). (c): aflD, 420 bp in non-aflatoxigenic isolate 3 (lane 1) and aflatoxigenic isolate 5 (lane 2)

CLUSTAL multiple sequence alignment (https://www.ebi.ac.uk/Tools/msa/) was used to align the deduced protein sequences of the isolated genes. Figure (2) showed that deduced protein sequence of aflR (our isolated gene) that consists of 86 amino acids, had $98.8 \%$, and $100.0 \%$ identity in 86 residues overlap With AFLR deduced amino acids sequence accession numbers, AAM02997 and AAM02991, respectively, while figure (3) illustrated $94.7 \%$ and $96.5 \%$ identity between aflS (our isolated gene) and that of AFLS accession numbers FN398166 and AF077975, respectively. Identity of $100.0 \%$ and $90.6 \%$ were detected in 138 residues overlap between aflD (in this study) and that of AFLD accession numbers AXG50934 and CAZ61375 as shown in Figure (4)

\begin{tabular}{|c|c|}
\hline $\begin{array}{l}\text { AAM02997.1 } \\
\text { AFLR } \\
\text { AAM02991.1 }\end{array}$ & $\begin{array}{l}\text { MVVLIVLKVLAWYAAAAGTQCTSTAAGGETNSGSCSNSPATVSSGCLTEERVLHLPSMMG } \\
\text { MVVLIVLKVLAWYAAAAGTQCTSTAAGGETNSGSCSNSPATVSSGCLTEERVLHLPSMMG } \\
\vdots \pm\end{array}$ \\
\hline $\begin{array}{l}\text { AAM02997.1 } \\
\text { AFLR } \\
\text { AAM02991.1 }\end{array}$ & 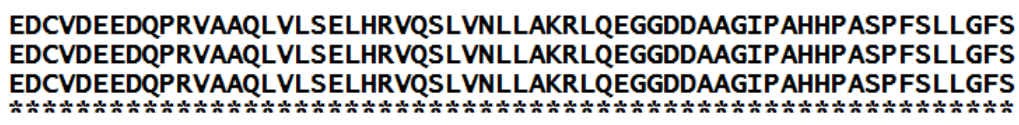 \\
\hline $\begin{array}{l}\text { AAM02997.1 } \\
\text { AFLR } \\
\text { AAM02991.1 }\end{array}$ & 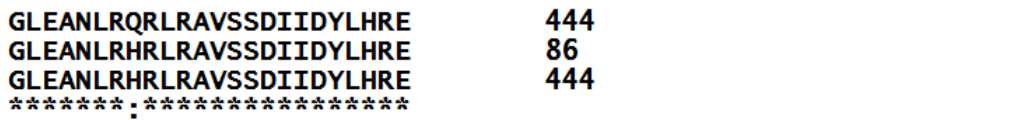 \\
\hline
\end{tabular}

Figure2. Alignment of deduced amino acid sequences of the AFLR accession no. BCD52745, AFLR, Accession no. AAM02991 and AFLR, Accession no. AAM02997

\section{AFLS \\ FN398166.1 AF077975.1 \\ AFLS \\ FN398166.1

作 FLCEPSPGHVAHSVLSKOFVTOPALLDAILFMSETLAPSASAMGTOTRRFGASEQAEDSA FLCEPSPGHVAHSVMSKQFVTQPALLDAILFMSETLAPSASAMGTQTRRFGASEQAEDSA

WNMAVGSDSPFAACLQQRLKVKRQLGDYLSWSSSIDAGVEDTLTRMNWQNLGMATWHV WNMAVGSDSPFAACLQQRPKVKRQLGAYLSWSSSIDAGVEDTLTRMNWQNLGMATVWVV WNMAVGSDSPFAECLQQRPKVKRQLGAYLSYVSSSIDAGVEDTLTRMNWQNLGMAT---V

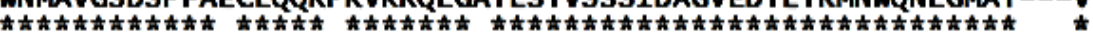

Figure 3.Alignment of deduced amino acid sequences of the AFLS (under submission), AFLS, Accession no. FN398166 and AFLS, Accession no. AF077975 


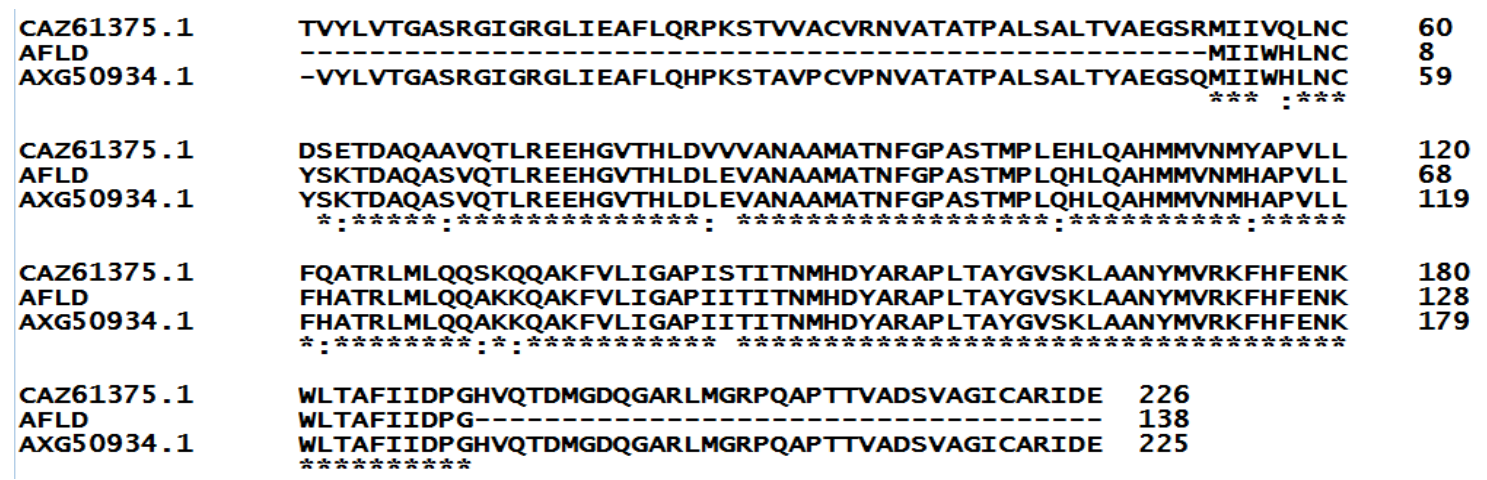

Figure 4. Alignment of deduced amino acid sequences of the aflD gene accession no. BCD52744, AFLD, Accession no. AXG50934 and AFLD, Accession no. CAZ61375.

\subsubsection{Effect of GA on Growth of Aflatoxigenic A. flavus and Aflatoxin Production}

Treatment of $A$. flavus strain no. 5 , as the highest aflatoxin producer, with $1 \%(\mathrm{w} / \mathrm{v})$ GA caused colony diameter reduction, besides the decrease in the formation of spores after three days of cultivation figure (5A) as compared with its growth on PDA medium not containing GA figure (5B). Simultaneously, production of aflatoxin in PDB Medium containing GA with $1 \%$ concentration (w/v) was significantly reduced from $34.97 \mathrm{ug} / \mathrm{ml}$ to $8.12 \mathrm{ug} / \mathrm{ml}$ as follow; AFB1yield decreased from 23.30 to 6.09 and that of AFB2 reduced from 11.67 to 2.03 (figure 6). We concluded that AF production was directly proportional to colony diameter in A. flavus, i.e. GA affected the growth and AF production negatively.

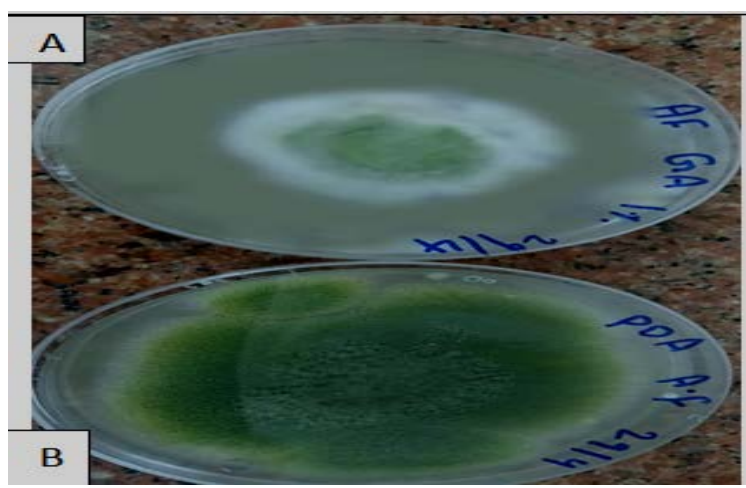

Figure 5. The effect of gallic acid on A. flavus growth, A: Growth of A. flavus on PDA containing $1 \%$ gallic acid (treatment). B: Growth of A. flavus on PDA (control) at $28^{\circ} \mathrm{C}$ after three days.

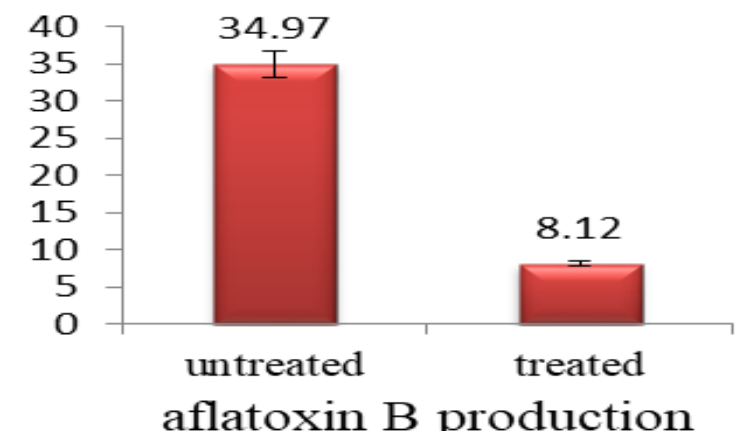

Figure 6. The effect of gallic acid on aflatoxin production from $A$ flavus isolates 5 in PDB containing $1 \%$ gallic acid (treated) compared with control at $28{ }^{\circ} \mathrm{C}$ after three days .
3.2.2. Analysis the Effect of GA on aflR, aflS and aflD Expression in Aflatoxigenic A. flavus using qRT-PCR

The increase in genes expression required for $\mathrm{AF}$ biosynthesis mainly depending on aflR transcription, supports the hypothesis that for AF-pathway induction, AFLR as transcription regulator is important, therefore, the blocking of undesirable AF production through designing approaches such as utilization of antioxidant substances requires understanding the mechanisms that are being followed by environmental and physiological factors and its effect on $a f l R$ transcription. From figure (7), expression analysis for transcripts of genes (aflR, aflS and aflD) in $1 \%$ gallic acid-treated aflatoxigenic A. flavus strain no. 5 indicated that these transcripts expression have to correlate GA treatment. Interestingly, all three assigned genes expressions significantly down regulated due to GA

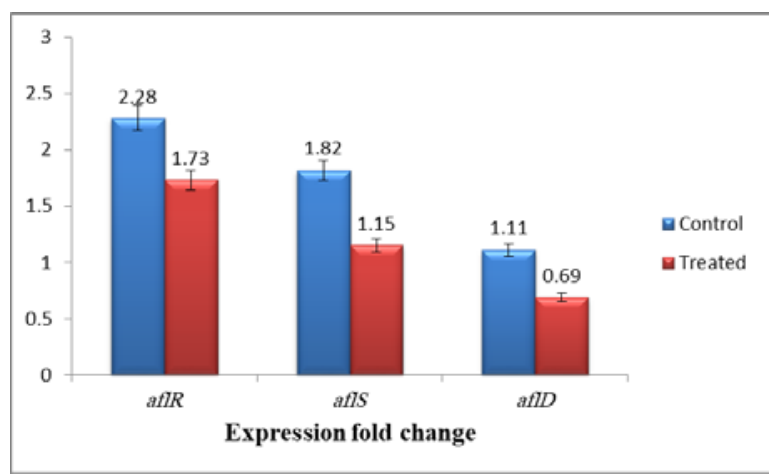

treatment of concentration of $1 \%(\mathrm{w} / \mathrm{v})$.

Figure 7. The effect of gallic acid on aflR, aflS and aflD expression in aflatoxigenic $A$. flavus using qRT-PCR

\section{Discussion}

Many Egyptian researchers directed their efforts for exploring the fungal contamination and their role in aflatoxin production in Egyptian crops. El-Shanshoury et al, (2014) investigated A. flavus in soybean, peanut seeds, wheat maize, and rice. As mentioned in the result section, the metabolic profile of mycotoxins in the aflatoxigenic $A$. flavus strains was similar to that reported in the study conducted by Rank et al, (2012), they announced the production of only B-types in A. flavus. Interestingly, the metabolism of mycotoxigenic fungi and its molecular genetics study is a good strategy to deal with mycotoxin contamination in crops (El-Kad and Youssef, 1993). It is 
of interest to discover and understand the genetic differences between aflatoxigenic and non-aflatoxigenic strains. This conclusion has been employed to direct these differences to control aflatoxin biosynthesis. In this study, traditional PCR technique was used to investigate the presence of three genes; the first is aflR, which is considered as an indicator for aflatoxin production in $A$. flavus and its homolog in A. parasiticus (apaR) that regulate aflatoxin biosynthesis (Woloshuk et al., 1994). Its role is to control nor- 1 and ver- 1 genes expression ( $\mathrm{Yu}$ et al., 2004). These genes are sufficient to stimulate transcription of early, mid, and late AF pathway biosynthesis genes. The second is aflS that positively regulates biosynthesis of AFB2 and the third gene is aflD, (formally, nor-1) as an important structure gene in aflatoxin cluster genes encodes norsolorinic acid reductase to convert norsolorinic acid to averantin (Payne et al., 1993). To connect the presence of aflR, aflS, and aflD genes profiles in aflatoxigenic and non-aflatoxigenic, a single set of PCR primers was used to detect these genes and reliably succeed in amplification of these genes in aflatoxigenic and non-aflatoxigenic $A$. flavus strains. These conflicting results can be explained as follows: specific mutation may occur in aflR, and resulted in malfunction gene and subsequently failure in aflatoxin production in non-aflatoxigenic isolates even though in the presence of functional copies of $a f l D$ and aflS. In a similar study conducted by Bok and Keller, (2004), they investigated and explained the block in omtA (a structural gene in AF biosynthesis expression in A. flavus although presence of AFLR, a protein encoded by aflR as follows: the presence of specific mutation in aflR resulted in nonfunctional AFLR, therefore, omtA expression did not take place. However, Liu and Chu, (1998) explained this phenomenon by the presence of a mutation in DNA binding site in omtA gene caused to not producing omtA mRNA. Similar nucleotide sequences of detected genes between aflatoxin producing and nonproducing strains told no information about the characterization of these genes. Consequently, this research concluded that successful PCR amplification of aflatoxin genes should not be considered as a proof of aflatoxin synthesis due to undetected mutation external to the amplicon sequence that subsequently caused cryptic and not expressed genes. The study conducted by Patterson (2006), demonstrated that the aflR gene may be present in a number of non-aflatoxigenic and functions for conserved regulation of aflatoxin precursors. Twelve strains of A. flavus were investigated by Shapira et al. (1996), nine of them were non-aflatoxin producers in which some genes involved AF biosynthesis were successfully PCR amplified in varying band patterns; however, only three strains were aflatoxin producers in which the expected amplicon bands were produced. From the previous notifications, the presence of un-expressed genes in non-aflatoxigenic strains may be explained by the occurrence of non-functional gene products due to basepair substitution mutations.

Our attempts were directed to inhibit the AF production by reducing the oxidative stress using antioxidant such as Gallic acid which proved its efficiency in diminishing of AF production in GA treated $A$. flavus isolate. In order to gain insight into the mechanism by which GA inhibits aflatoxin synthesis, we employed qRT-PCR to assess the expression of aflS, aflR, and aflD. Down regulation of these genes in GA treated sample as compared with untreated one explain the reason of diminishing of aflatoxin production. Mahoney and Molyneux, (2004) illustrated the role of GA in the inhibition of expression of several genes in AF pathway such as aflM (ver-1). Another study was conducted by Zhao et al, (2018), they used gallic acid as an antioxidant agent to reduce aflatoxin production. Addition of gallic acid in different doses $(0.5 \%, 0.8 \%$, and $1 \%)$ slightly inhibited aflatoxin and growth of A. flavus; they showed the inhibition of AF by $0.8 \%$ of GA on farB gene encodes a factor for transcription of $\beta$-oxidation of peroxisomal fatty acid which contributes in AF biosynthesis. Another gene, creA, the carbon repression regulator encoding gene and necessary for aflatoxin biosynthesis, was also inhibited by GA treatment. Total inhibition for AF by gallic acid treatment was through the control of polyketide synthase (fatty acid synthase) required for the formation of norsolorinic acid, the first intermediate in the biosynthesis pathway of aflatoxin. It is striking that we noticed incompatibility between our results and the results of Zhao et al, (2018) in terms of the effect of GA on the expression of aflR and aflS, gallic acid concentration of $0.8 \%(\mathrm{w} / \mathrm{v})$ inhibited nearly all the genes of aflatoxin except $a f l R$ and aflS.

In our research, taking these results together, we proposed that the down regulation of aflR as a master gene in AF regulation may result in down regulation of other genes such as aflS and $a f I D$; this explanation is agreed with Cotty (2006) who acknowledged that introduction of an additional correct copy of the aflR compensates for the disrupted one in A. flavus and caused the transcription of AF biosynthesis structural genes and aflatoxin intermediates production. Clevstrom et al. (1983) also studied the inhibition of the biosynthesis of AF caused by aflR transcription delay as well as other cluster genes of AF by induction anti-oxidant enzymes via b-glucans from Lentinulaedodes. The previously reported studies, besides our research, proved the potential of gallic acid in biosynthesis inhibition of aflatoxin in A. flavus through the expression modulating of aflR, aflS and aflD.

\section{Conclusion}

Successful PCR amplification of specific genes such as aflR, aflS, and aflD should not be considered evidence of biosynthesis of aflatoxin due to the lack of gene expression as a result of cryptic form and undetected mutation outside to the amplicon sequence and this conclusion explained presence of aflR, aflS, and aflD genes in aflatoxigenic and non-aflatoxigenic $A$. flavus isolates by traditional PCR using genomic DNA as a template. In addition, upon finding that GA as antioxidant, it was used to effectively suppress aflatoxin synthesis. Interestingly, qRT-PCR, a potential tool was employed to investigate the effects of GA on the transcription of aflatoxin genes, aflR, aflS, and $a f I D$, as these genes were down-regulated.

\section{Acknowledgment}

The authors thank the National Research Centre at Dokki, Cairo, Egypt for laboratory assistance. 


\section{References}

Ausubel FM, Brent R, Kingston RE, Moore DD, Seidman JG, Smith JA and Kevin S.1990. Current Protocols in Molecular Biology. In: the polymerase chain reaction Mullis $\mathrm{KB}$, Ferre F, Gibbsditors RA (eds.)

Bhatnagar D, McCormick SP, Lee LS and Hill RA. 1987. Identification of $\mathrm{O}-$ methylsterigmatocystin as aflatoxin $\mathrm{Bi}$ and Gl precursor in Aspergillus parasiticus. Appl Environ. Microbiol., 53:1028-1033.

Bok JW and Keller NP. 2004. LaeA, a Regulator of Secondary Metabolism in Aspergillus spp. Eukaryot Cell, 3: 527-535

CalvoAM, Bok J, Brooks W and Keller NP. 2004. VeA is required for toxin and sclerotial production in Aspergillus parasiticus. Appl Environ Microbiol., 70: 4733-4739.

Carbone I, Ramirez-Prado JH, Jakobek JL and Horn BW. 2007. Gene duplication, modularity and adaptation in the evolution of the aflatoxin gene cluster. BMC EvolBiol, 7: 111

Chang PK. 2004. Lack of interaction between AflR and AflJ contributes to non-aflatoxigenicity of Aspergillus sojae. $J$ Biotechnol., 107: 245-253.

Clevstrom G, Ljunggren H, Tegelstrom S and Tideman K. 1983 Production of aflatoxin by an Aspergillus flavus isolate cultured under a limited oxygen supply. Appl Environ Microbiol., 46: 400405.

Cotty PJ, Barug D, Bhatnagar D, van-Egmond HP, van der Kamp JW, van Osenbruggen WA and Visconti A. 2006. Bio competitive exclusion of toxigenic fungi. In the Mycotoxin Factbook, Eds, Wageningen Academic Publishers: Wageningen, The Netherlands: 400p

Desjardins AE and Proctor RH. 2007. Molecular biology of Fusarium mycotoxins. Int J Food Microbiol., 119: 47-50.

Du W, O’brian GR and Payne GA. 2007. Function and regulation of aflJ in the accumulation of aflatoxin early pathway intermediate in Aspergillus flavus. Food Addit Contam., 24: 10431050 .

Duncan DB. 1955. Multiple ranges and multiple $\mathrm{F}$ test Biometrics., 11:11-24

Ehrlich KC, Yu J and Cotty PJ. 2005. Aflatoxin biosynthesis gene clusters and flanking regions. J Appl Microbiol., 99: 518-527.

El-Kady IA and Youssef MS. 1993.Survey of mycoflora and mycotoxins in Egyptian soybean seeds. J Basic Microbiol., 33 371-378.

El-Shanshoury AR, El-Sabbagh SM, Emara HA and Saba HE. 2014. Occurrence of moulds, toxicogenic capability of Aspergillus flavus and levels of aflatoxins in maize, wheat, rice and peanut from markets in central delta provinces, Egypt. Int J Curr Microbiol App Sci., 3: 852-865.

Färber P, Geisen R and Holzapfel W. 1997.Detection of aflatoxigenic fungi in figs by a PCR reaction.Int $J$ Food Microbiol., 36: 215-220.

Giorni P, Magan N., Pietri A, Bertuzzi T and Battilani P. 2007. Studies on Aspergillus section Flavi isolated from maize in northern Italy. Int J Food Microbiol., 113: 330-338.

Jelinek CF, Pohland AE and Wood GE. 1989. Review of mycotoxin in food and feeds-an update. J Assoc Anal Chem.,72: 223-230.

Kim JH, Yu J, Mahoney N, Chan KL and Molyneux RJ. 2008. Elucidation of the functional genomics of antioxidant-based inhibition of aflatoxin biosynthesis. Int J Food Microbiol., 122 49-60.
Lee JW, Roze LV and Linz JE. 2007. Evidence that a wortmannin-sensitive signal transduction pathway regulates aflatoxin biosynthesis. Mycologia., 99: 562-568.

Liu B and Chu F. 1998. Regulation of $a f l R$ and its product, AflRS, associated with aflatoxin biosynthesis. Appl Environ Microbiol., 64: 3718-3723.

Mahoney N and Molyneux RJ. 2004. Phytochemical inhibition of aflatoxigenicityin Aspergillus flavus by constituents of walnut (Juglansregia). J Agric Food Chem., 52: 1882-1889.

Mahrous KF, Abd El - Kader HA, Mabrouk DM, Aboelenin MM, Osman NM, Khalil WK and Hassanane MS. 2020. Molecular characterization and expression analysis of hepc1 and hepc2 in three tilapia species collected from Lake Manzala. Bulletin of the National Research Centre., 44: 1-13.

Meyers DM, O’brian G, Du WL, Bhatnagar D and Payne GA. 1998. Characterization of aflJ, a gene required for conversion of pathway intermediates to aflatoxin. Appl Environ Microbiol., 64: 3713-3717.

Nesbitt BF, O'Kelly J, Sargeant $\mathrm{K}$ and Sheridan A. 1962.Aspergillus flavus and turkey X disease, toxic metabolites of Aspergillus flavus. Nature., 195: 1062-1063.

O’Brian GR, Georgianna DR, Wilkinson JR, Yu J, Abbas HK, Cleveland D,Bhatnagar TE, Nierman W and Payne GA. 2007.The effect of elevated temperature on gene transcription and aflatoxin biosynthesis. Mycologia., 99: 232-239.

Patterson R. 2006. Identification and quantification of mycotoxigenic fungi by PCR. Process Biochemistry., 41: 14671474.

Payne G, Nystorm G, Bhatnagar D, Cleveland T and Woloshuk C. 1993. Cloning of the afl-2 gene involved in aflatoxin biosynthesis from Aspergillus flavus. Appl Environ Microbiol., 59: $156-162$.

Price MS. 2005. Classical and modern genetic approaches reveal new gene associations with aflatoxin biosynthesis in Aspergillus parasiticus and $A$. flavus. Ph.D. Thesis.

Rahimi KP, Sharifnabi B and Bahar M. 2008. Detection of aflatoxin in Aspergillus species isolated from pistachio in Iran. $J$ Pathol., 156: 15-20.

Rank C, Klejnstrup ML, Petersen LM, Kildgaard S, Frisvad JC, Gotfredsen HC and Ostenfeld LT. 2012. Comparative Chemistry of Aspergillus oryzae (RIB40) and A. flavus (NRRL 3357). Metabolites., 2: 39-56.

Reverberi M, Zjalic S, Ricelli A, Punelli F and Camera E. 2008. Modulation of antioxidant defence in Aspergillus parasiticus is involved in aflatoxin biosynthesis: a role for ApyapA gene. Eukaryot Cel.,l 25: 25.

Ruijter JM, Ramakers C, Hoogaars WM, Karlen Y, Bakker O, Hoff MJ and Moorman AF. 2009. Amplification efficiency: linking baseline and bias in the analysis of quantitative PCR data. Nucleic Acids Res., 37:45.

Salim RG , Aly SE, Abo-Sereh NA, Hathout AS and Sabry BA. 2019. Molecular identification and Inter-Simple Sequence Repeat (ISSR) differentiation of toxigenic Aspergillus Strains. Jordan J Biol Sci., 12:609-616

Shapira R, Paster N, Eyal O, Menasherov M, Mett A and Salamon R. 1996. Detection of aflatoxigenic molds in grains by PCR. Appl and Environmen Microbiol., 62: 3270-3273.

Thompson JD, Higgins DG and Gibson TJ. 1994. CLUSTAL W: improving the sensitivity of progressive multiple sequence alignment through sequence weighting, position-specific gap penalties and weight matrix choice. Nucleic acids res., 22: 46734680 . 
Todd RB and Andrianopoulos A. 1997. Evolution of a fungal regulatory gene family: the $\mathrm{Zn}$ (II)2Cys6 binuclear cluster DNA binding motif. Fungal Genet Biol., 21: 388-405.

Woloshuk CP, Foutz KR, Brewer JF, Bhatnagar D, Cleveland TE and Payne GA. 1994. Molecular characterization of aflR, a regulatory locus for aflatoxin biosynthesis. Appl Environ Microbiol., 60: 2408-24014.

Yan S, Liang Y, Zhang J and Liu CM. 2012.Aspergillus flavus grown in peptone as the carbon source exhibits spore densityand peptone concentration-dependent aflatoxin biosynthesis. BMC Microbiol., 12: 106-112.

Yu JH, Bhatnagar D and Cleveland TE. 2004. Completed sequence of aflatoxin pathway gene cluster in Aspergillus parasiticus. FEBS Lett., 564: 126-130.
Yu JH and Ehrlich KC. 2002. Aflatoxin biosynthesis.Rev Iberoam Micol., 19: 191-200.

Yu JH, Butchko RA, Fernandes M, Keller NP, Leonard TJ and Adams TH. 1996. Conservation of structure and function of the aflatoxin regulatory gene aflR from Aspergillus nidulans and $A$. flavus. Curr Genet., 29: 549-555.

Zhao X, Qing-Qing Z, Jie-Ying L, Nancy P, Keller ID and Zhu MH. 2018. The Antioxidant Gallic Acid Inhibits Aflatoxin Formation in Aspergillus flavus by Modulating Transcription Factors FarB and CreA .Toxin., 10: 2-17. 
Appendix

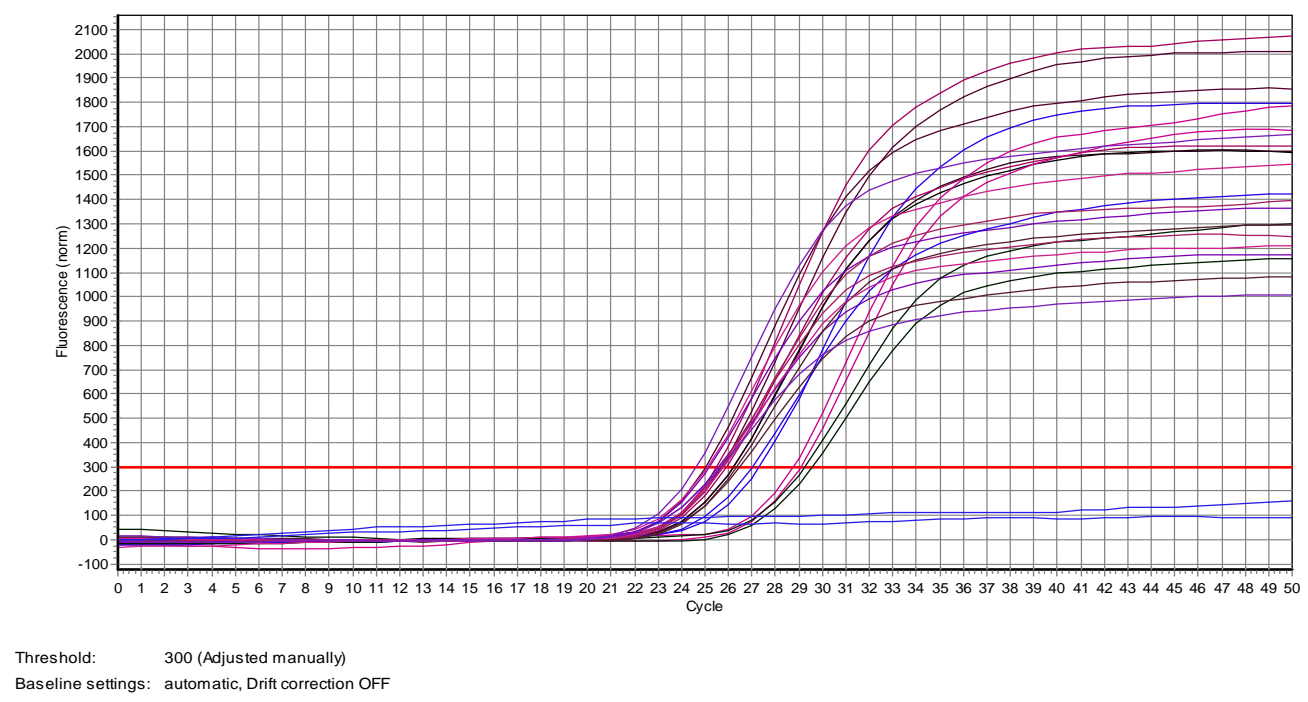

The linear and log amplification curves representing the Ct values of aflR gene.

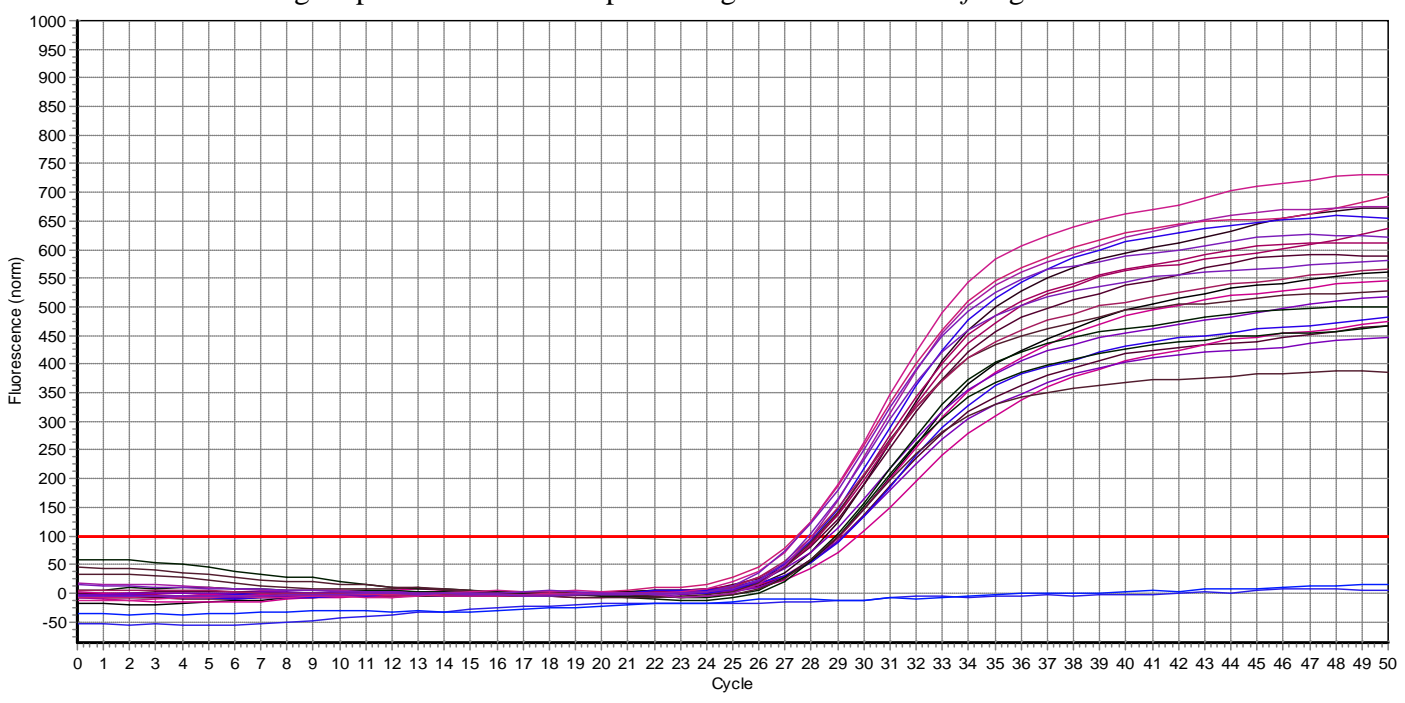

Threshold: 100 (Adjusted manually)

Baseline settings: automatic, Drift correction OFF

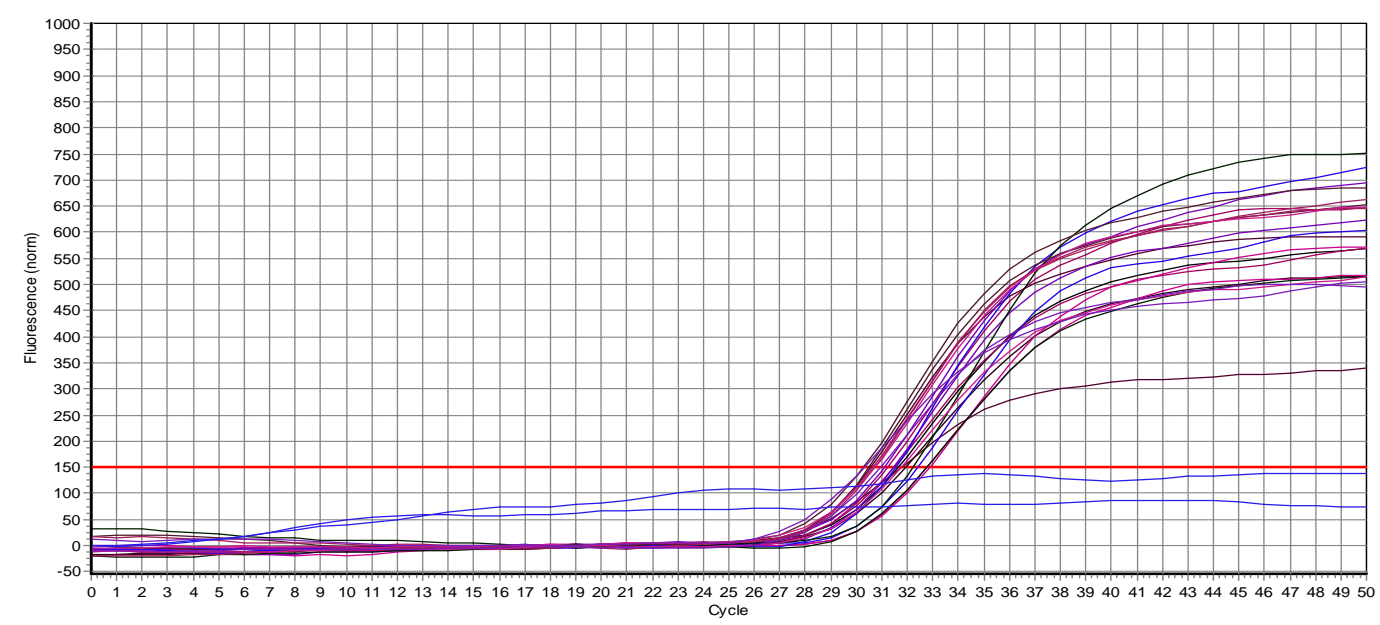

Threshold:

150 (Adjusted manually)

Baseline settings: automatic, Drift correction OFF 